\title{
THE GENERIC NAME TROMBICULOIDES JACOT, $1938^{1}$
}

By G. W. Wharton

Department of Zoölogy, Duke University

Jacot (1938) obtained some specimens of mites and identified them as Trombidium scabrum Say, 1821. However, he realized that his specimens were not representative of the genus Trombidium. Therefore the new generic name Trombiculoides was proposed, with Trombidium scabrum designated as type. His generic diagnosis was based however, on his specimens and not on Say's description. Say's description was disregarded whenever a discrepency arose between the specimens and the description.

Ewing 1946 reported that Jacot had misidentified his specimens and that Trombidium scabrum was in reality a species of Sericothrombium. Ewing therefore considered Trombiculoides a synonym of Sericothrombium Berlese, 1910. Furthermore he points out that Howard (1918) had given an excellent account of the species including figures of both larval and adult stages. It is obvious from the descriptions of Howard and Jacot that they are not dealing with the same or even closely related species. On the other hand it is also obvious that Say's description is so incomplete that his name $T$. scabrum might apply to any one of several species in different families, or might refer to a concept that includes a complex of several species.

Jacot's specimens were borrowed from the Museum of Comparative Zoölogy through the courtesy of Dr. Bequaert. A study of the specimens showed that they were compared with specimens of Eutrombicula alfreddugèsi Oudemans, 1910 from cultures, and no significant differences between the two could be noted. It is impossible to identify Jacot's specimens as Eutrombicula alfreddugèsi at the present time, however, because this species can be

1 This paper is a report on work done in connection with a Grant-in-Aid from the Research Grants Division of the U. S. Public Health Service. 
recognized as distinct from Eutrombicula masoni (Ewing, $1943)$ only on the basis of larval characteristics.

According to Opinion 168 of the International Commission on Zoölogical Nomenclature, "it is to be assumed that the original author of a genus correctly identified the species assigned by him there to, . . . . but that, where there is evidence that .... (this) assumption(s) is at variance with the facts, the case should be submitted with full details to the International Commission on Zoölogical Nomenclature, and that pending their decision thereon, the genus should be regarded as of doubtful status.',

In this case it seems that there is evidence that Jacot misidentified the specimens on which he based Trombiculoides. The facts will be presented to the International Commission on Zoölogical Nomenclature. It therefore follows that until the Commission acts, Trombiculoides Jacot, 1938 must be considered as of doubtful status.

Fortunately Eutrombicula Ewing, 1938, the name now used for the genus that includes the specimens on which Jacot based his Trombiculoides, has priority over Trombiculoides Jacot, 1938. The date of Eutrombicula is 15 June 1938 while that of Trombiculoides is 10 October 1938. Therefore no change in the generic names is anticipated in settling the status of Trombiculoides Jacot, 1938.

\section{REFERENCES}

Ewing, H. E. 1938. A key to the genera of chiggers (mite larvae of the sub-family Trombiculinæ) with descriptions of new genera and species. J. Wash. Acad. Sci., 28 : 288-295.

Ewing, H. E. 1946. Notes on the taxonomy of three genera of trombiculid mites (chigger mites), together with the description of a new genus. Proc. Biol. Soc. Wash., 59: 69-72.

Jacot, A. P. 1938. Thomas Say's free-living mites rediscovered Psyche. Boston, 45: 121-132.

Say, T. 1821. An account of the arachnids of the United States. Jour. Acad. Nat. Sci., Philadelphia, 2: 59-83. 

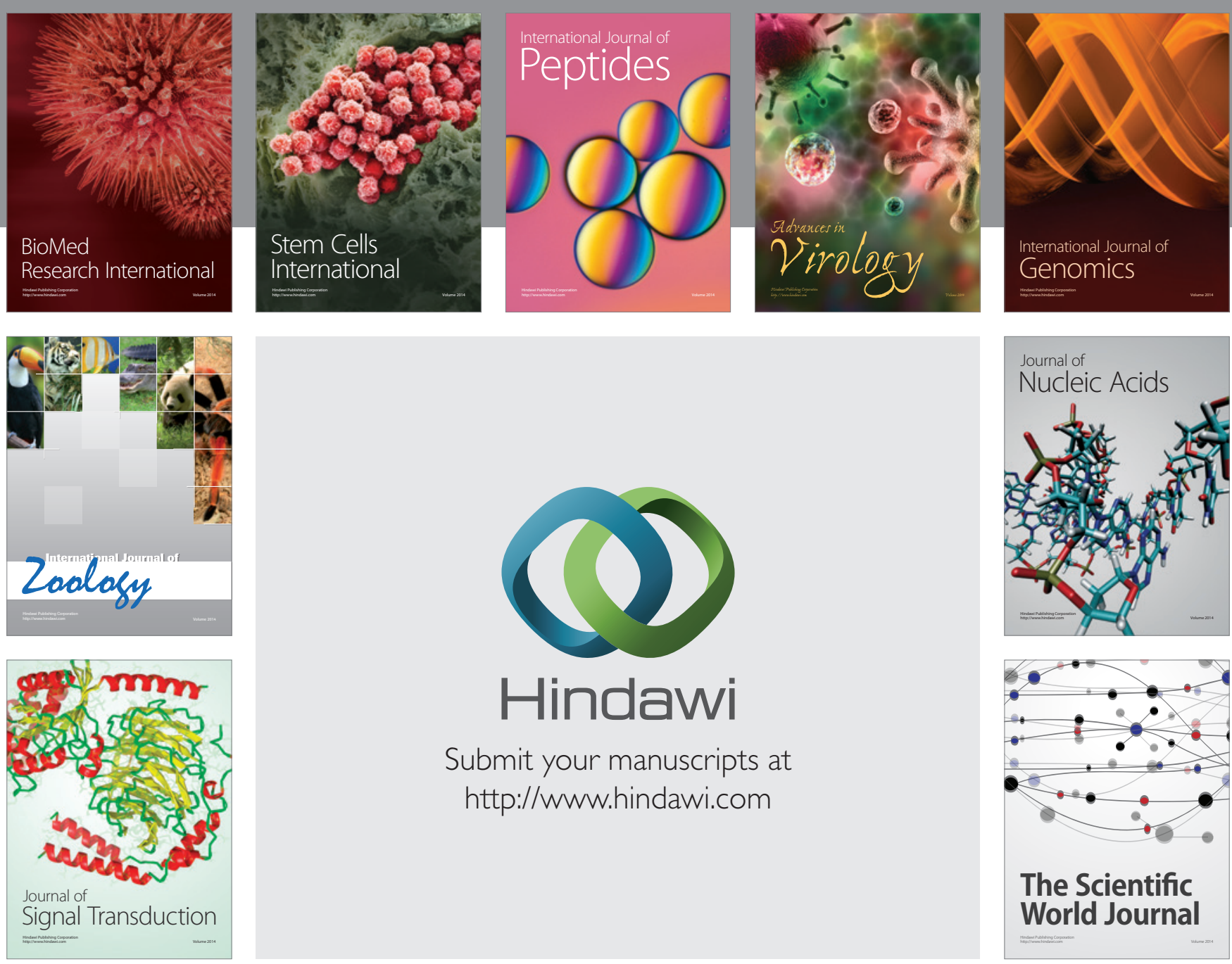

Submit your manuscripts at

http://www.hindawi.com
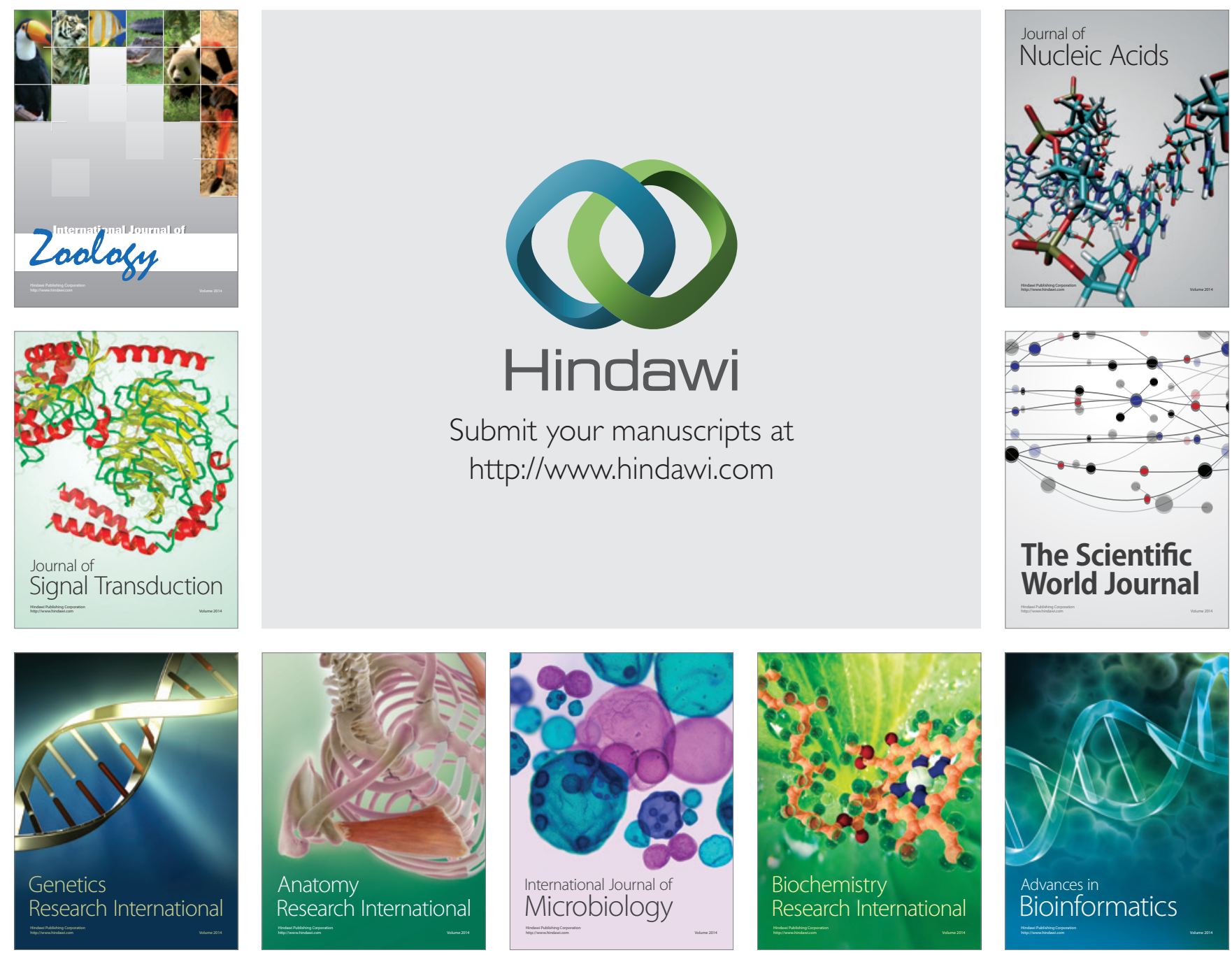

The Scientific World Journal
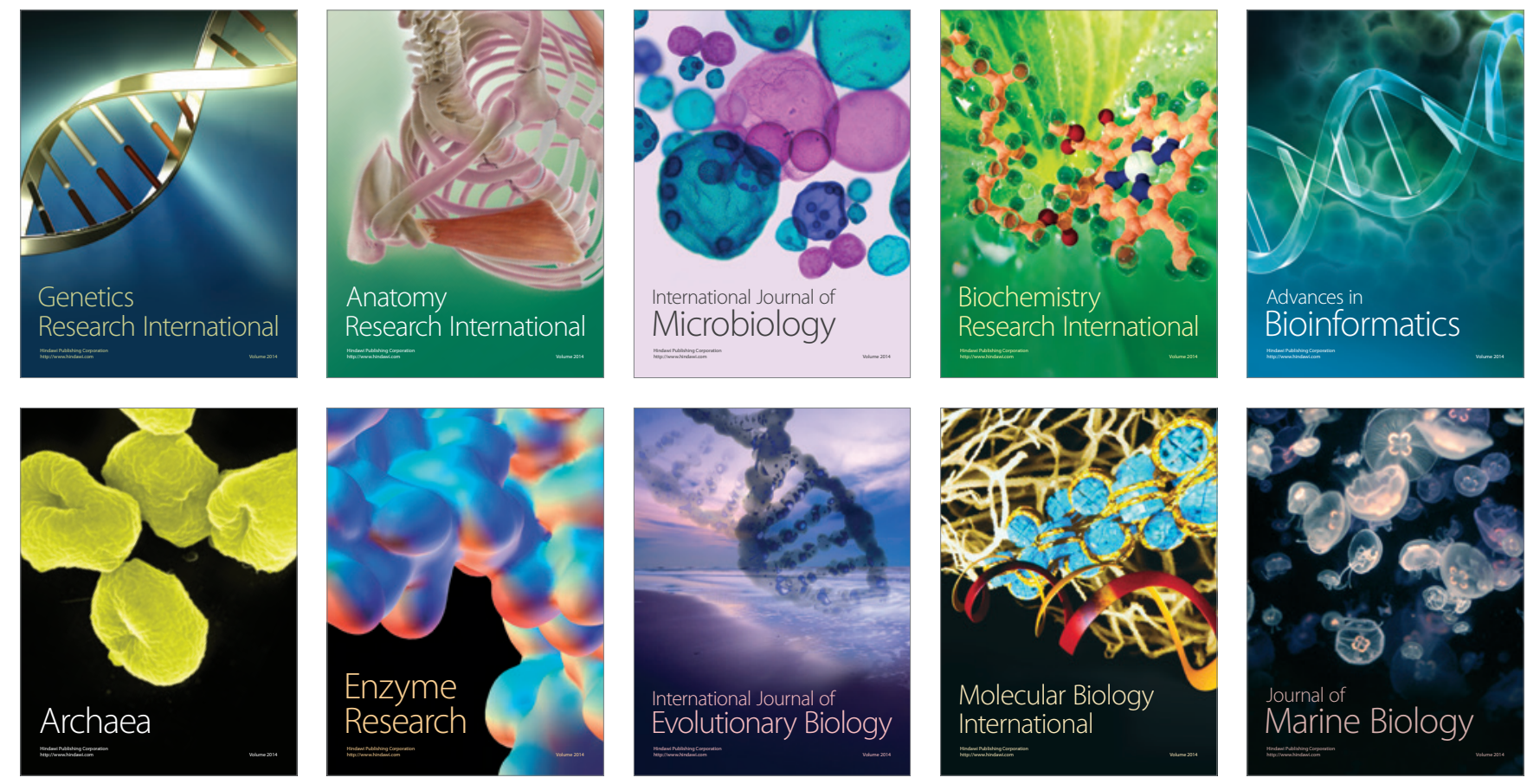